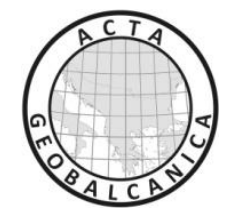

\title{
MAPPING OF THE MICRORELIEF STRUCTURES USING MULTITEMPORAL VERY HIGH RESOLUTION SPACE IMAGERY
}

\author{
Evgeny Panidi ${ }^{1}$, Julia Sokolova ${ }^{1}$, Lubov Trofimetz $^{2}$ \& Elena Kunaeva ${ }^{3}$ \\ ${ }^{1}$ Saint-Petersburg State University, Russia \\ ${ }^{2}$ Orel State University, Russia \\ ${ }^{3}$ Pushkin Leningrad State University, Russia \\ Corresponding author: e.panidi@spbu.ru,j.sokolova@spbu.ru
}

\begin{abstract}
Described case study is a part of research project focused on investigation of the capabilities and techniques of microrelief mapping based on different data sources. The case study was conducted to estimate the effectiveness and accuracy of microrelief mapping using the multitemporal very high resolution satellite images. Used test area is located at North-Western Russia (Leningrad region, Tosna river basin). GigitalGlobe's WorldView-1 and 2 satellite images were used. The DSM modelling, DSM accuracy estimation and microrelief structures interpretation were conducted.
\end{abstract}

Keywords: DSM, Microrelief Mapping, Very High Resolution Space Imagery, Multitemporal Space Imagery.

\section{INTRODUCTION}

Many types of big-scale (i.e., detailed) environmental research demand information about microrelief (landforms with dimensions from few meters to a few tens of meters) [9], [12]. It could be Digital Elevation Models (DEMs), as well as Digital Surface Models (DSMs) or some derivative data, like gridded maps of quantitative microrelief parameters, or digitally mapped microrelief structures (e.g., thalwegs, watersheds, etc.). This information produced previously using expensive (in all senses) field surveys. Being big-scale formations, microrelief structures have relatively high evolution dynamics. As a result, the techniques are needed for automation of repeated microrelief modelling and mapping. This issue could be resolved using remote sensing data collection and interpretation. However, the study of remote sensing data quality and accuracy is needed, to establish data characteristics demanded for correct microrelief modelling. This is the aim of our studies.

Studies of other authors show that the very high resolution (sub-meter spatial resolution) space imagery collected in the stereo mode makes it possible to produce the DSMs with 5 meter accuracy of height measurements in the case of images georeferenced without ground control points (GCPs) [1]. GCPs help to reduce errors and to produce DSMs with sub-meter accuracy [8], [11], and with accuracy higher than $10 \mathrm{~cm}$ in the case of 
additional reduction of systematic biases [2]. In the case of northern territories, it could be problematic to collect qualitative data, due to climate and weather conditions. In particular, for satellite-based remote sensing it is usual problem, when cloud coverage prevents data collection in appropriate time. Additionally, the absence of the same-date stereo pairs in data archives is usual, when the study area located out of the urbanized territories. In this context, the issue of multitemporal stereo imagery use becomes actual.

\section{USED DATA AND PROCESSING METHODS}

We produced our case study on ground test area (Fig. 1) which is located in Russia's Leningrad region, in the Tosna river basin (approximate coordinates are the $30^{\circ} 47^{\prime} 19.65^{\prime \prime}$ of east longitude and 59 $40^{\prime} 25.49^{\prime \prime}$ of north latitude).

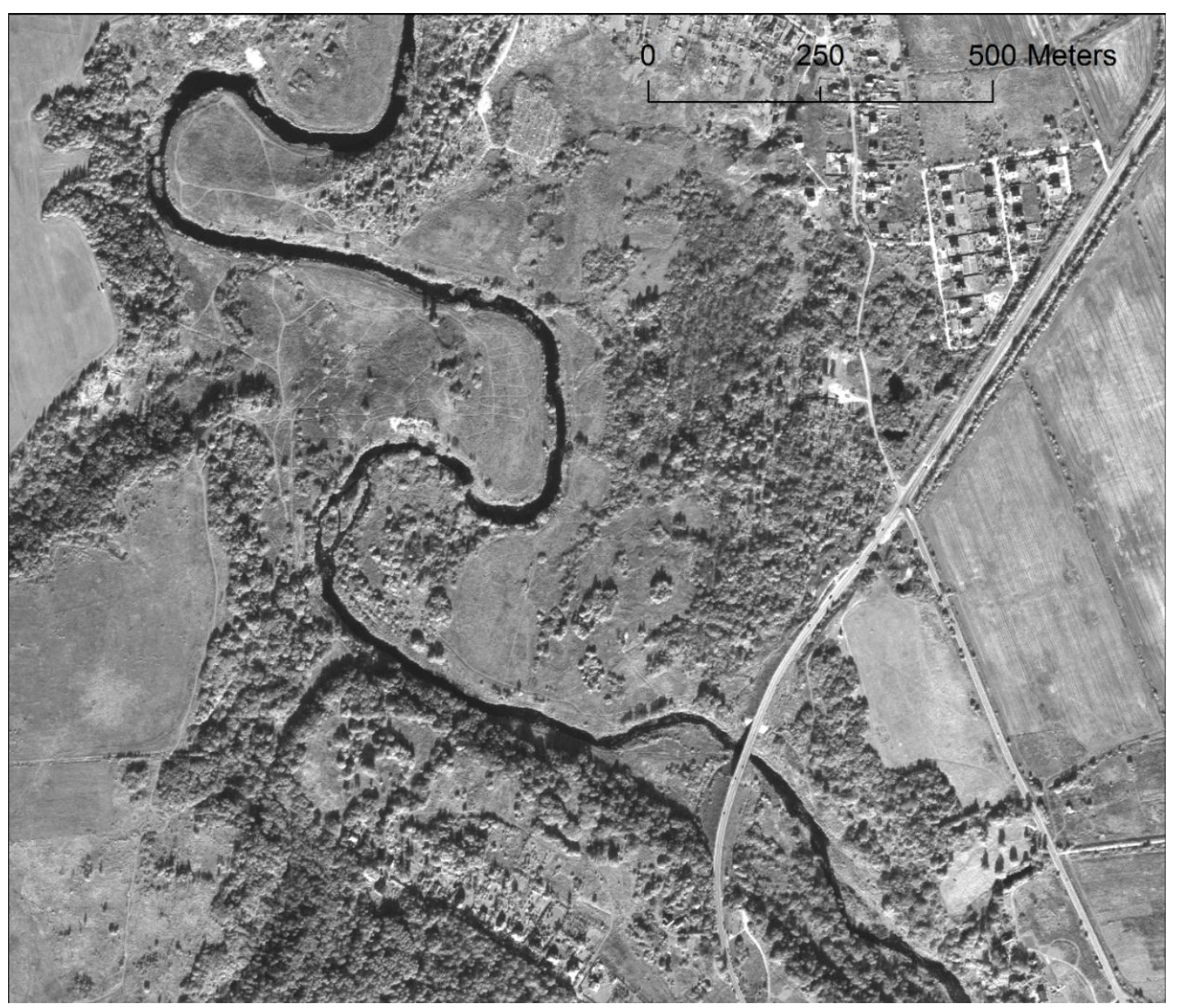

Figure 1. Image of the ground test area. Image courtesy of the DigitalGlobe Foundation.

Initial Data. To extract DSMs we used four WorldView-1,2 Basic Ortho-Ready images [6] with nominal spatial resolution of $0.5 \mathrm{~m} / \mathrm{pix}$. Two WorldView-1 images were collected as stereo pair on February 22, 2012. Other two WorldView-2 images were collected as single images on 9 and 20 September, 2014. The last two were used to compose multitemporal stereo pair. All images had the RPC-based georeference.GCPs for georeference correction were collected using detailed $(0.1 \mathrm{~m} / \mathrm{pix})$ orthomosaic of 
our test area [3]. Additionally, the heights of GCPs were extracted from SRTM ${ }^{1}$ DEM V2.1.

Software. We used the Erdas Imagine ${ }^{2}$ software. The LPS tool was used to produce block triangulation and adjustment, Classic ATE tool - to produce automatic extraction of DSMs, and Stereo Analyst tool - to interpret and extract microrelief structural lines.

Vertical datum. The EGM $96^{3}$ Earth Gravitational Model was used to consider the conversion between the geodetic heights (heights above Earth's ellipsoid model, which are used for purposes of RPC-based georeferencing, block triangulation and DSM extraction) and ortometric heights (heights above Earth's geoid model, which are approximate the normal heights traditionally used in surveing).

DSM extraction parameters. The procedure of DSM extraction was produced in standard manner [5], [10]. It is based on the automated image matching technique, which implies extraction of matching points on the two overlapping images basing on the search for pixels of corresponding contrast and brightness.

The following parameters were set for Classic ATE tool. Cell size was specified as 1 meter, i.e. double sized spatial resolution of WorldView-1,2 panchromatic channels. An advanced Adaptive ATE algorithm was activated for fine tuning of the extraction process. Expected DSM accuracy was set to $5 \mathrm{~m}$, which is the vertical accuracy of WorldView-1,2. All block triangulation points (GCP, Check and Tie) and external (referential) SRTM DEM were used in extraction process, for more accurate extraction of the DSM.

Microrelief interpretation techniques. To interpret microrelief structures we used manual technique. The interpretation was produced using the anaglyph-based 3D visualisations of the stereo pairs. This technique helped us to collect 3D points located on the structural lines of microrelief landforms (in equal places on both stereo pairs). In particular, we collected points at upland edges, hill bottoms and stream thalwegs. These points made it possible to produce quality analysis and accuracy estimations of interpretation of the microrelief structures. Currently, we have interpreted only the structural lines that can be recognized easily on the images in manual mode.

\section{RESULTS AND ANALYSIS}

In the result of DSM extraction produced for both stereo pairs, we generated two surface models. In order to provide DSM extraction, the images were georeferenced and the block triangulation adjustment was performed for both stereo pair. Three GCP points and three check points were used for each stereo pair. Total root mean square error (RMSE) of the adjustment reached 0.67 pixels for the same-date stereo pair and 0.76 pixels for multitemporal stereo pair.

Unfortunately, the standard-way DSM extraction gave an appropriate result only for the case of same-date stereo pair (Fig. 2). The DSM produced from the multitemporal stereo pair has too many artefacts end errors, probably due to the land cover change that took place in 11 days between images acquisition.

\footnotetext{
${ }^{1}$ http://dds.cr.usgs.gov/srtm/version2_1/SRTM3/Eurasia/

${ }^{2}$ http://www.hexagongeospatial.com/products/producer-suite/erdas-imagine

${ }^{3}$ http://cddis.nasa.gov/926/egm96/egm96.html
} 
However, the anaglyph visualisation produced for the multitemporal stereo pair (Fig. 3) is fully applicable for visual study of the territory and for the interpretation of objects and relief structures. Moreover, the mode of automatic cursor adjustment to the surface, that is accessible in Stereo Analyst tool, worked properly in most cases.

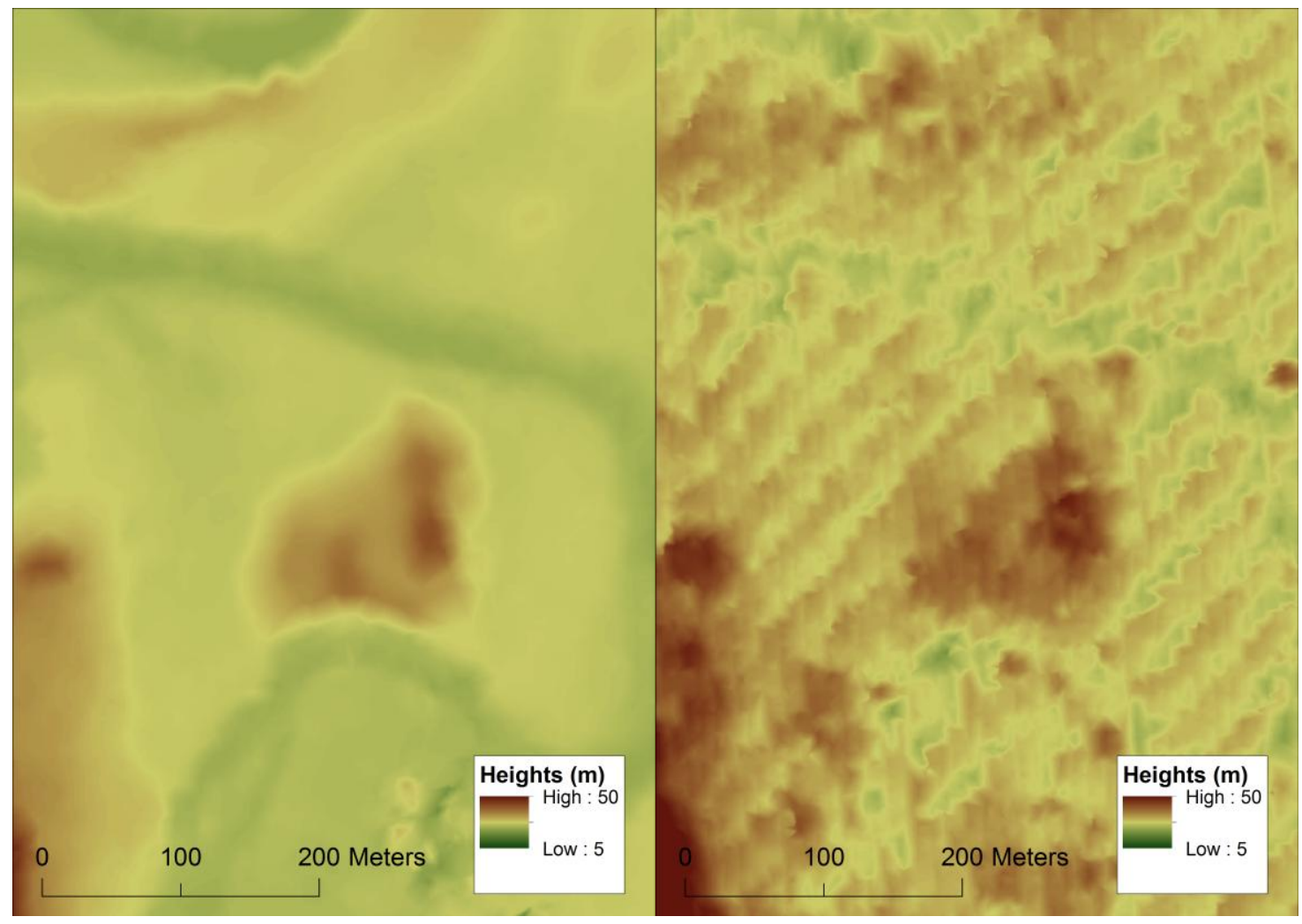

Figure 2. DSMs produced from same-date stereo pair (left image) and from multitemporal stereo pair (right image).

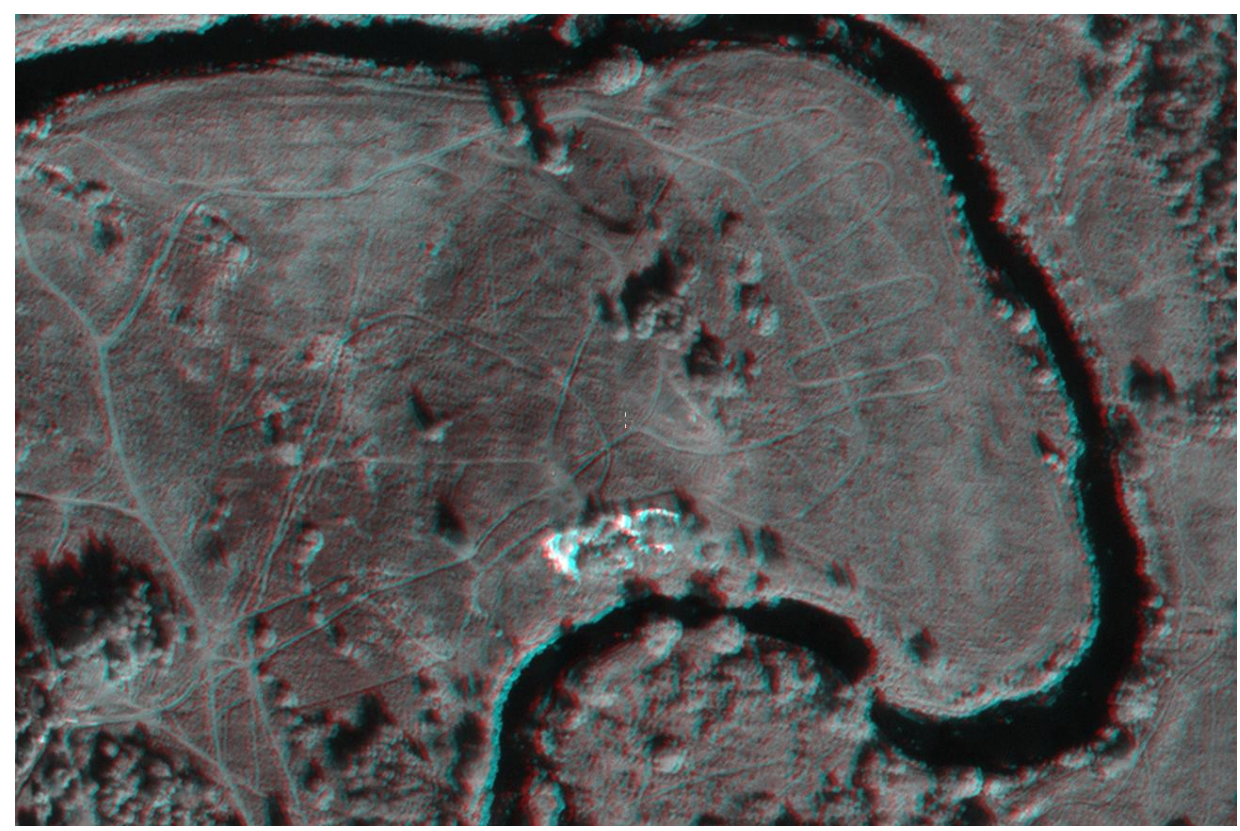

Figure 3. Fragment of the multitemporal stereo model (this anaglyph image can be viewed as a $3 \mathrm{D}$ using anaglyph red/blue glasses). Images courtesy of the DigitalGlobe Foundation. 
Described stage of our study assumes only the cameral investigations, without verification by field surveys. Due to this, we used comparative techniques to estimate the accuracies of produced DSMs (for the case of same-date stereo pair only) and interpreted microrelief structures (for both cases).

DSM accuracy estimations. To produce accuracy estimation we used 33 reference points (points of the geodetic reference network presented on the test area). Maximum value of the absolute error at reference points was the $2.9 \mathrm{~m}$, and the minimum value was the $0.5 \mathrm{~m}$. RMSE was the $2.0 \mathrm{~m}$.

Microrelief accuracy estimations. Accuracy of the microrelief structures interpretation we produced in two ways. The first one was the comparison of the horizontal and vertical differences in positions of the manually collected points of structural lines and the DSM surface. The second was the comparison of equal points of structural lines located on the same-date and on the multitemporal stereo pairs.

For the estimation of horizontal biases in positions of manually interpreted structural lines and structural lines that can be extracted from the DSM, we produced maps of catchment area [4] and profile curvature [7]. These two geomorphometric variables traditionally used to build DEM-based algorithms for relief structures interpretation. For each interpreted point, we measured the horizontal displacement (Fig. 4) between the point position and closest line of catchment area maximal values in the case of stream thalwegs, closest line of profile curvature maximal values in the case of upland edges, and closest line of profile curvature minimal values in the case of hill bottoms. Maximum value of the horizontal displacement (i.e. error) was registered as the $4.5 \mathrm{~m}$, the RMSE value was the $1.4 \mathrm{~m}$, and the $90 \%$ linear error was the $2.6 \mathrm{~m}$.

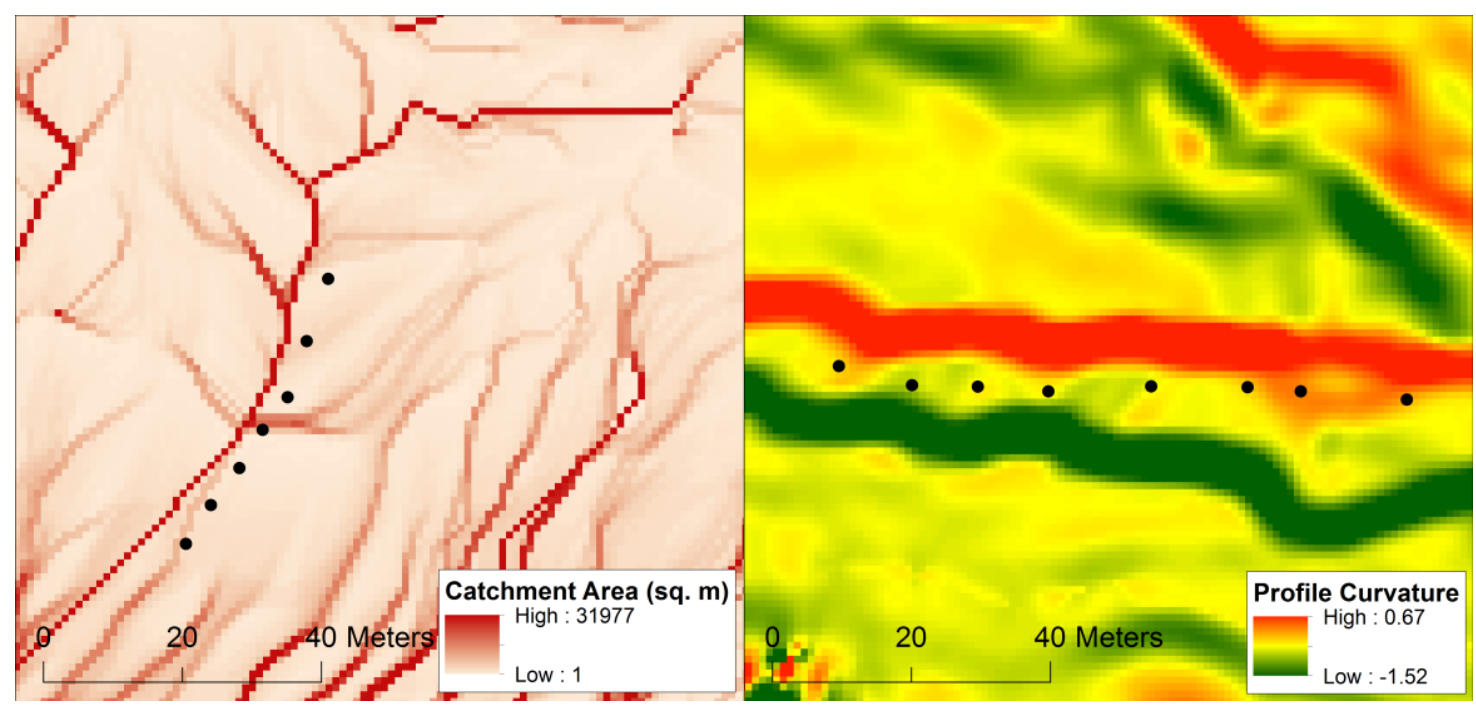

Figure 4. Location of the stream thalweg points (black points) relative to the line (dark red line) of maximal catchment area values (left image), and location of the upland edge points (black points) relative to the line (wide red line) of maximal profile curvature values (left image).

Additionally, estimations for vertical displacements of positions of the collected points relative to the DSM surface were registered. Maximum absolute displacement (i.e. error) was the $4.0 \mathrm{~m}$, RMSE was the $0.8 \mathrm{~m}$, and the $90 \%$ linear error was the $1.6 \mathrm{~m}$.

Vertical displacements between the structural lines measured on the same-date and multitemporal stereo pairs were estimated on the point to point basis and show next 
results. Maximum absolute displacement (i.e. error) was the $4.5 \mathrm{~m}$, minimum absolute error was the $1.3 \mathrm{~m}$, the RMSE value was the $1.8 \mathrm{~m}$, and the $90 \%$ linear error was the $3.3 \mathrm{~m}$.

\section{CURRENT CONCLUSIONS AND FUTURE WORK}

Currently we produced first results of the quality and accuracy estimations for interpretation of microrelief structures on the very high resolution stereo pairs. The general conclusion is that the interpretation of the microrelief structures on the very high resolution images is possible. Estimated interpretation accuracies do not exceed the declared georeference accuracy of used images (which is $5 \mathrm{~m} \mathrm{[6]).} \mathrm{These} \mathrm{interpretation}$ accuracies are applicable for example in the case of thematic investigations that deal with field data sampling with the help of GNSS receivers (for sampling points coordinating).

Additionally, we can conclude that the accuracy of microrelief interpretation on the multitemporal stereo pair is comparable to the same-date stereo pair. This finding makes it possible to use pairs of single images instead of stereo pairs, which are rarely available or unavailable for many territories.

However, produced work shows that the issue of quality enhancement of automated DSM extraction from the multitemporal stereo needs to be investigated. In addition, we may conclude that the technique of manual interpretation of the microrelief structures should be formalised to minimize the measurement errors.

\section{ACKNOWLEDGEMENTS}

The study was partially supported by Russian Foundation for Basic Research (RFBR), research project No. 15-05-07463 A.

Used satellite images courtesy of the DigitalGlobe Foundation.

\section{REFERENCES}

[1] Cheng P., Chaapel C. Using WorldView-1 Stereo Data with or without Ground Control Automatic DEM Generation. Geoinformatics, Volume 11, No. 7, 2008, pp. 34-37.

[2] Baskakov S. Highly accurate relief modeling for designing of Kundyzdy and Limannoe mines infrastructure based on remote sensing. Geomatics, Volume 2(19), 2013, pp. 80-86 (in Russian).

[3] Bliakharskii D.P. Digital aerial survey of the training ground polygon «Sablino» using UAV. Proceedings of the international scientific-practical conference dedicated to the 20th anniversary of the Saint-Petersburg society of geodesy and cartography, 2012 p. 47 (in Russian).

[4] Costa-Cabral M.C., Burges S.J. Digital Elevation Model Networks (DEMON): A model of flow over hillslopes for computation of contributing and dispersal areas. Water Resources Research, Volume 30, Issue 6, 1994 pp. 1681-1692. doi: 10.1029/93WR03512

[5] DigitalGlobe. Digital Terrain Model Extraction using WorldView-2 Stereo and ERDAS LPS Automated Terrain Extraction. Available at 
http://global.digitalglobe.com/sites/default/files/DEM_extraction_from_OR2A_Ster eo_and_ERDAS_LPS.pdf

[6] DigitalGlobe. Data Sheet. Standard Imagery. Available at http://global.digitalglobe.com/sites/default/files/StandardImagery_DS_1014_forWeb.pdf

[7] Evans L.S. General geomorfometry, derivatives of altitude, and descriptive statistics. In: Chorley R.J. (ed.), Spatial Analysis in Geomorfology, London, Methuen \& Co. Ltd., Chapter 2, 1972. pp. 17-90.

[8] Mitchell G. Digital terrain models generated by satellite stereo imagery and laser scanning data: comparative analysis. Geomatics, Volume 4(9), 2010, pp. $54-57$ (in Russian).

[9] Panidi E., Trofimetz L., Sokolova J. A study of indicative methods applied to microrelief mapping. International Symposium on Digital Earth, October 5-9, 2015, Halifax, Nova Scotia, Canada, Abstract Volume, 2015, p. 15.

[10]Poli D., Caravaggi I. Digital surface modelling and 3D information extraction from spaceborne very high resolution stereo pairs. 2012, 31 p. doi:10.2788/15526

[11] Saldaña M.M., Aguilar M.A., Aguilar F.J., Fernández I. DSM Extraction and Evaluation from Geoeye-1 Stereo Imagery. ISPRS Annals of the Photogrammetry, Remote Sensing and Spatial Information Sciences, Volume I-4, 2012, pp. 113-118. doi:10.5194/isprsannals-I-4-113-2012

[12] Trofimetz L., Panidi E. Study of soil loss quantity on the arable territories using estimations of soil pollutants migration and geomorphometric parameters of the microrelief. SGEM2015 Conference Proceedings, Book 3, Volume 2, 2015, pp. 341-348. doi:10.5593/SGEM2015/B32/S13.046 